\title{
Using Modified Mortar-Bar Test Method to Access the Effects of Deicers on Expansion of Mortars With and Without Reactive Aggregates
}

\author{
Yi-Cheng Chiu and Jan Olek \\ School of Civil Engineering, Purdue University
}

\begin{abstract}
The influence of deicing chemicals on alkali reactivity of aggregates is still an area of active research. The potential alkali reactivity of aggregates is often tested using the ASTM C1260 method. This research used the modified ASTM C1260 to test the potential alkali reactivity of aggregates. The modification included replacing the standard $1 \mathrm{~N}$ sodium hydroxide $(\mathrm{NaOH})$ used in ASTM $\mathrm{C} 1260$ with eutectic concentrations of the three common chloridebased deicing chemicals: sodium chloride $(\mathrm{NaCl})$, magnesium chloride $\left(\mathrm{MgCl}_{2}\right)$, and calcium chloride $\left(\mathrm{CaCl}_{2}\right)$. The results showed that the mortar bars with reactive aggregate (Jobe sand) stored in $\mathrm{NaCl}$ solution developed higher expansion than those stored in $\mathrm{MgCl}_{2}$ and $\mathrm{CaCl}_{2}$ solutions. It seems $\mathrm{NaCl}$ can initiate (or accelerate) the alkali silica reaction (ASR), while $\mathrm{MgCl}_{2}$ and $\mathrm{CaCl}_{2}$ do not seem to contribute to ASR. In addition, after about 100-120 days of exposure, irrespective of whether they contained reactive (Jobe sand) or nonreactive (Ottawa sand) aggregates, the mortar bars submerged in the $\mathrm{MgCl}_{2}$, solution started to crack and disintegrate. This implies that the observed expansions should be attributed solely to the effect of these deicers on the cement paste itself rather than to their effects on aggregates. The proposed modified test method produced conclusive results within a relatively short testing time ( $\sim 28$ days).
\end{abstract}

Keywords: accelerated expansion test, alkali silica reaction, chloride-based deicers, mortar bars.

\section{INTRODUCTION}

The durability of Portland cement materials is strongly influenced by the length of exposure to environmental loads (e.g., moisture, temperature, freezing and thawing cycles, weathering) and to traffic loads. It can also be compromised by poor selection of the mixture components (e.g., high alkali cement, alkali-reaction susceptible aggregate, frost-susceptible aggregate, high water-cement ratio), or poor construction practices (e.g., lack of curing or improper compaction and finishing).

This study investigated the durability of Portland cement-based mortars containing both nonreactive and alkali-reaction susceptible aggregates while exposed to deicing chemicals. One of the goals of the study was to develop a test method for determination of potential alkali reactivity of aggregates in concretes exposed to deicing chemicals. The mortar bar test method (ASTM Standard C1260, 2007) is still one of the most popular methods used to determine the potential alkali reactivity of aggregates in concrete, while the effect of deicing chemicals on Portland cement materials is often evaluated by such experiments as freezing and thawing $(F / T)$ test, wetting and drying (W/D) tests, and so on.

In his study on the effects of deicers on the alkali silica reaction (ASR) behavior of mortars, Desai (2010) used the ASTM C1260 test method and showed that mortar bars containing reactive aggregate and exposed to $3 \mathrm{wt} \% \mathrm{NaCl}$ and $\mathrm{KCl}$ solutions expanded more than the same type of specimens exposed to standard $1 \mathrm{~N} \mathrm{NaOH}$ solution. The same study also showed that 28 days exposure of mortar bars to hot $\left(80^{\circ} \mathrm{C}\right)$ solutions of $\mathrm{CaCl}_{2}$ and $\mathrm{MgCl}_{2}$ did not cause ASR. It was also found that there were no significant differences in the expansion of mortar bars prepared with cements of different alkali content while they were exposed to the deicing solutions. Other researches (Kawamura \& Ichise, 1990; Kawamura, Takeuchi, \& Sugiyama, 1994) conducted pore solution analysis of concrete specimens immersed in $\mathrm{NaCl}$ solution at $38^{\circ} \mathrm{C}$. The results illustrated that chloride ions played an important role in raising hydroxyl ion concentration in the pore solution and in acceleration of the ASR.

Berube and Frenette (1994) compared the ASR expansion results of concretes tested at $38^{\circ} \mathrm{C}$ with those performed at $80^{\circ} \mathrm{C}$ and concluded that expansion levels achieved during the 28 days of exposure at $80^{\circ} \mathrm{C}$ will require up to 6 months of exposure at $38^{\circ} \mathrm{C}$.

Using the above-mentioned information to accelerate the ASR process, all specimens used in this study, were prepared with high alkali cement and the expansion experiments were conducted in $80^{\circ} \mathrm{C}$ oven. 


\section{EXPERIMENTAL}

This study involved performing the accelerated mortar bar expansion test based on the modified ASTM C1260 test method. The modification included replacing the $1 \mathrm{~N} \mathrm{NaOH}$ solution used in the standard test method with various deicers. Other environment conditions were kept the same in the ASTM C1260.

The tests were performed on mortar bars prepared from reactive aggregate (Jobe sand crushed to 1260 gradation) as well as a nominally nonreactive (control) aggregate (Ottawa sand of ASTM C778 20/30 gradation). This gradation designation requires the sand to pass \#20 sieve ( $850 \mu \mathrm{m}$ mesh opening) and be retained on \#30 sieve (600 $\mu \mathrm{m}$ mesh opening).

The Jobe sand is a highly alkali reactive natural sand (Ghajar-Khosravi, 2011), while Ottawa sand is composed almost entirely of naturally rounded grains of nearly pure quartz.

All mortars were mixed and cast as per the procedure in ASTM C305 (ASTM Standard C305, 2006). Once cast, the mortar bar specimens were covered with a damp burlap/cloth and were cured in the curing room $\left(\sim 100 \%\right.$ relative humidity $(\mathrm{RH})$ and $\left.23^{\circ} \mathrm{C}\right)$ for $24 \mathrm{~h}$. After that, the initial length readings were taken, and the bars were then placed in the container with $\mathrm{DI}$ water stored in $80^{\circ} \mathrm{C}$ oven for $24 \mathrm{~h}$. The 0 day length reading was taken after the $24 \mathrm{~h}$ of $80^{\circ} \mathrm{C}$ exposure to $\mathrm{DI}$ water. After finishing the measurement, the specimens were placed in their soak solutions.

Table 1 shows the exposure matrix used during the study. During the test, the mortar bars were submerged in several liquids, including: the deionized water (DI water), $1 \mathrm{~N} \mathrm{NaOH}$, and three different deicers of nearly eutectic compositions. These deicers included the following: $23 \mathrm{wt} \% \mathrm{NaCl}$, $25 \mathrm{wt} \% \mathrm{MgCl}_{2}$, and $28 \mathrm{wt} \% \mathrm{CaCl}_{2}$. These particular concentrations of deicers were selected to yield a roughly identical concentration of ionic species in each of the solutions. The dimensions of the mortar bars were $1^{\prime \prime} \times 1^{\prime \prime} \times 11^{\prime \prime}$.

Table 1. Exposure matrix used in this study.

\begin{tabular}{lc}
\hline Mortars & Exposure solutions \\
\hline Ottawa sand & DI Water \\
& $1 \mathrm{~N} \mathrm{NaOH}$ \\
& $23 \mathrm{wt} \% \mathrm{NaCl}$ \\
& $25 \mathrm{wt} \% \mathrm{MgCl}_{2}$ \\
& $28 \mathrm{wt} \% \mathrm{CaCl}_{2}$ \\
\hline Jobe sand & $\mathrm{DI} \mathrm{Water}$ \\
& $1 \mathrm{~N} \mathrm{NaOH}$ \\
& $23 \mathrm{wt} \% \mathrm{NaCl}$ \\
& $25 \mathrm{wt} \% \mathrm{MgCl}_{2}$ \\
& $28 \mathrm{wt} \% \mathrm{CaCl}_{2}$ \\
\hline
\end{tabular}

Figures 1 and 2 show the mortar bars in the soak solution $(\mathrm{NaOH})$ and in the sealed containers placed in the oven, respectively. The subsequent length readings were taken periodically for up to (approximately) 500 days.

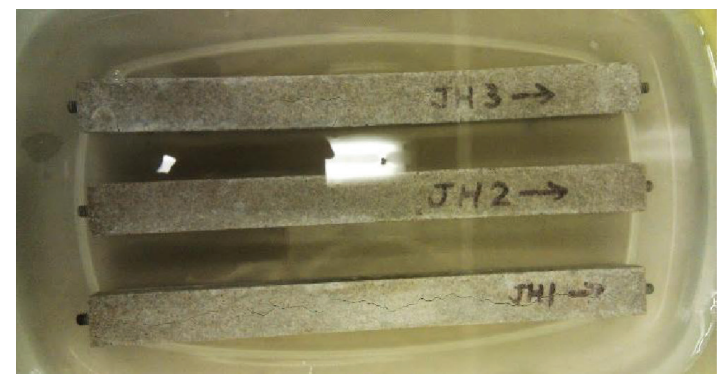

Figure 1. Mortar bars with Jobes and in the $\mathrm{NaOH}$ soak solution.

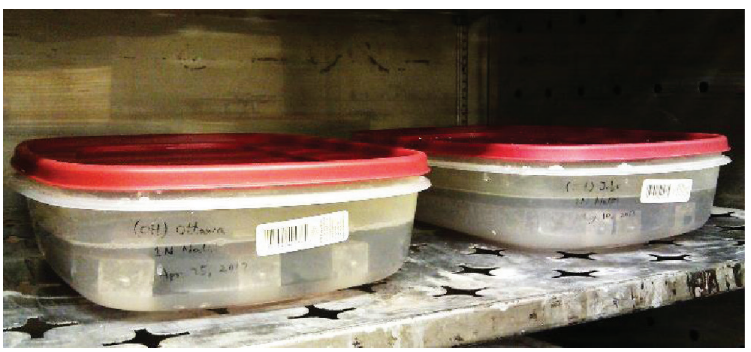

Figure 2. Mortar bars in the sealed containers in the $80^{\circ} \mathrm{C}$ oven.

\section{EXPERIMENT RESULTS}

\subsection{Length changes of mortar bars during the short (up to 28 days) exposure period}

The results of length change measurements collected during the short (up to 28 days) exposure period for the specimens with Ottawa sand are shown in Figure 3. These results show that the expansion of all mortar bars during the first 14 days of exposure is less than $0.10 \%$. The mortar bars stored in the $\mathrm{MgCl}_{2}$ solution show low $(\sim 0.04 \%)$ initial (during the first 2 days) shrinkage after which they started a slow expansion and almost reach their original length (i.e., they showed $0 \%$ expansion) at 28 days. However, at 28 days, the mortar bars immersed in $\mathrm{CaCl}_{2}$ solution expanded up to $0.13 \%$.

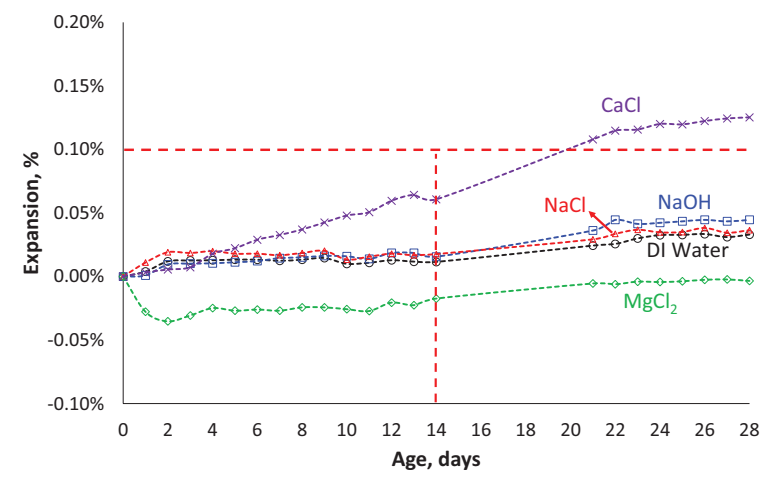

Figure 3. Expansion of mortar bars with non-reactive aggregate (Ottawa sand) during short exposure period (28 days). 
Table 2 shows the recommended expansion limit in ASTM C1260. Based on these limits, expansions lower than $0.10 \%$ at 16 days after casting (or after 14 days of exposure) are indicative of mostly innocuous behavior. On the other hand, expansions of more than $0.20 \%$ at 16 days after casting are indicative of potentially deleterious expansion.

Table 2. Recommended expansion limit in ASTM C1260.

\begin{tabular}{|c|c|}
\hline $\begin{array}{l}\text { Expansion at } \\
16 \text { days after } \\
\text { casting (14 days } \\
\text { measurement) }\end{array}$ & Description of mortar bar specimens \\
\hline$<0.10 \%$ & Innocuous behavior \\
\hline$>0.20 \%$ & Potentially deleterious expansion \\
\hline $0.10-0.20 \%$ & $\begin{array}{l}\text { Aggregates that are known to be innocuous } \\
\text { and deleterious in field performance. (It may } \\
\text { also be useful to take comparator readings } \\
\text { until } 28 \text { days.) }\end{array}$ \\
\hline
\end{tabular}

Since the short-term expansion values of mortar bars with Ottawa sand exposed to $1 \mathrm{~N} \mathrm{NaOH}$ solution were just $\sim 0.02 \%$, using the limits shown in Table 2 will classify this aggregate as nonreactive.

As seen from Figure 4, the expansion values of mortar bars with Jobe sand stored in $\mathrm{NaCl}$ and $\mathrm{NaOH}$ solutions were much higher than the expansions of Ottawa bars stored in any of the soak solutions. Specifically, the 14 days' expansions of Jobe specimens stored in $\mathrm{NaCl}$ and $\mathrm{NaOH}$ solutions were, respectively, about 0.73 and $0.61 \%$ at 14 days. The 14 days' expansion of Jobe specimens stored in $\mathrm{CaCl}_{2}$ solution was $0.11 \%$.

The Jobe mortar bars stored in $\mathrm{MgCl}_{2}$ showed some initial shrinkage (comparable with that observed in mortars with nonreactive aggregate) after which they continued to expand at a very minimal rate. Finally, since the 14 days' expansion of Jobe bars stored in $1 \mathrm{~N}$ $\mathrm{NaOH}$ solution was up to $0.61 \%$, this aggregate would definitely be classified as the reactive using the ASTM C1260 criteria.

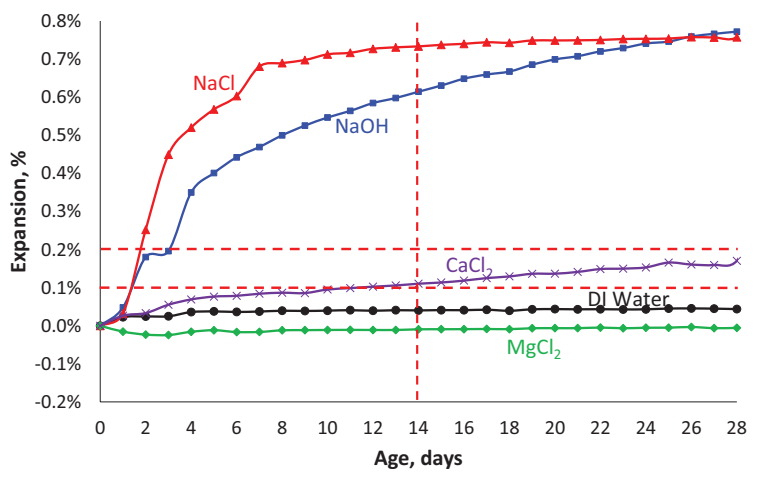

Figure 4. Expansion of mortar bars with reactive aggregate (Jobe sand) during the short exposure period (up to 28 days).
The comparison of expansions of mortar bars with Ottawa sand and Jobe sand is shown in Figure 5. This data clearly indicate that the mortar bars with Jobe sand stored in $\mathrm{NaCl}$ solution expanded very rapidly during the first 8 days of exposure. Subsequently, the rate of expansion slowed significantly and became negligibly small after 14 days. The mortar bars with Jobe sand stored in $\mathrm{NaOH}$ solution continued to expand during the entire 28 days monitoring period.

The mortar bars with Jobe sand immersed in $\mathrm{CaCl}_{2}$ solution showed slightly higher $(\sim 0.03 \%)$ expansion than specimens with Ottawa sand. There were no significant differences in expansion of the specimens with Jobe sand or Ottawa sand immersed in DI water and $\mathrm{MgCl}_{2}$ solution.

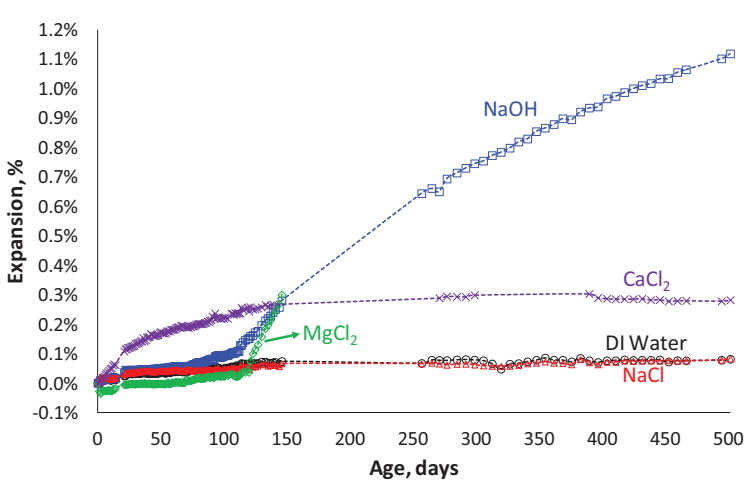

Figure 5. Comparison of expansion of mortar bars with Ottawa sand and Jobe sand during the short (28 days) exposure period.

\subsection{Length changes of mortar bars during the long (up to $\mathbf{5 0 0}$ days) exposure period}

This section describes the expansion of the Jobe sand and Ottawa sand mortar bars exposed to the same solutions as those used during the short-term test periods (i.e., $23 \mathrm{wt} \% \mathrm{NaCl}, 25 \mathrm{wt} \% \mathrm{MgCl}_{2}, 28 \mathrm{wt} \%$ $\mathrm{CaCl}_{2}$, and two control soak solutions of $1 \mathrm{~N} \mathrm{NaOH}$ and DI water) for the period up to 500 days. All exposure experiments were conducted at $80^{\circ} \mathrm{C}$.

As seen from Figure 6, the expansion of the mortar bars prepared with nonreactive aggregate (Ottawa sand) and immersed in the $\mathrm{DI}$ water and $\mathrm{NaCl}$ solution is showing a slight upward trend and reaches a value of about $0.07 \%$ after 146 days of exposure. This is a maximum value of observed expansion (in these solutions), and it did not change upon further exposure (up to 502 days). The set of mortar bars exposed to $\mathrm{CaCl}_{2}$ solution expanded at an accelerated rate during the first 20 days. After that, the bars continued expanding at a lower rate and reached expansion of about $0.27 \%$ after 139 days of exposure. At this point, the rate of expansion slowed considerably and remained essentially constant until the age of about 500 days. 


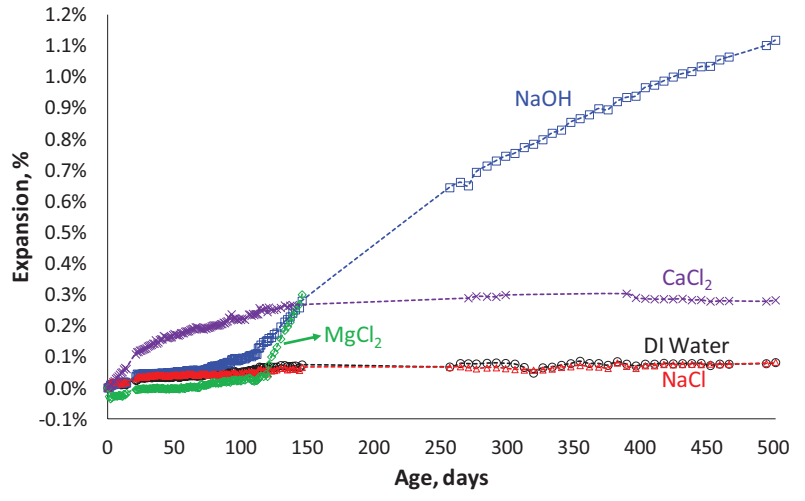

Figure 6. Expansion of mortar bars with nonreactive aggregate (Ottawa sand) during the long exposure period (up to 502 days).

The expansion of bars exposed to $\mathrm{NaOH}$ solution was moderate for about the first 100 days, but then it accelerated and reached the value of about $1.12 \%$ at 502 days. After undergoing a slight ( $0.04 \%)$ shrinkage during the first 2 days, the mortar bars stored in $\mathrm{MgCl}_{2}$ solution started slow expansion, reaching the level of about $0.04 \%$ at 120 days.

Interestingly, the rate of expansion of mortars exposed to $\mathrm{MgCl}_{2}$ solution increased significantly after the second replacement of the soak solution (at 120 days), and at 146 days, the expansion was around $0.30 \%$. At that point, the bars started to crack and quickly disintegrated. Similar increase in the rate of expansion was also observed for the bars exposed to the $\mathrm{NaOH}$ solution, although, in this case, it did not coincide with the replacement of the soak solution. Likewise, the replacement of the solution did not change the expansion levels of bars exposed to the $\mathrm{DI}$ water, $\mathrm{NaCl}$, and $\mathrm{CaCl}_{2}$ solutions.

Based on the research reported elsewhere (Desai, 2010), the $\mathrm{MgCl}_{2}$ and $\mathrm{CaCl}_{2}$ solutions do not seem to initiate or accelerate the ASR. These observations, combined with the fact that the data shown in Figure 6 were collected for bars with nonreactive aggregate, imply that the observed expansions should be attributed solely to the effects of these deicers on the cement paste itself and not on the aggregate. On the other hand, the data presented in Figure 6 for the expansion in the $\mathrm{NaOH}$ solution indicated that even the nominally nonreactive aggregate will start reacting upon prolonged exposure to high temperature and high concentration of the $\mathrm{Na}^{+}$ions.

The expansion values for mortar bars prepared with the reactive aggregate (Jobe sand) are shown in Figure 7.

The bars immersed in $\mathrm{NaCl}$ solution show significant expansion during the initial stages of exposure reaching the value of about $0.70 \%$ after 10 days. After that point, the expansion stabilized and remained roughly constant (at about $0.82 \%$ ) for the remainder of the test period (up to 501 days). In contrast, the same mortar bars exposed to $\mathrm{NaOH}$ solution continued

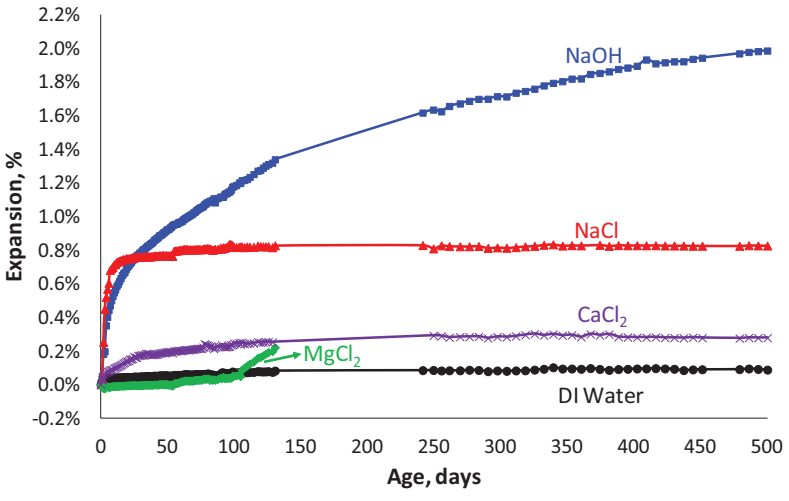

Figure 7. Expansion of mortar bars with reactive aggregate (Jobe sand) during the long exposure period (501 days).

to expand during the entire 501 days test period, reaching the value of expansion of about $2.0 \%$. The mortar bars exposed to $\mathrm{CaCl}_{2}$ solution also expanded, but the level of expansion was much lower than that observed for bars stored in $\mathrm{NaCl}$ and $\mathrm{NaOH}$ solutions.

The mortar bars stored in $\mathrm{MgCl}_{2}$ solution show some initial shrinkage (during the first 3 days) after which they continue to expand. After replacement of the soak solution (at 105 days), the rate of expansion of these bars increased sharply and eventually the bars disintegrated (after reaching the value of expansion of $0.22 \%$ at the age of 131 days). Similar to what was observed with the nonreactive aggregate samples immersed in $\mathrm{MgCl}_{2}$ solution, the replacement of the soak solution seems to have resulted in the increase in the rate of expansion. It should be pointed out that the replacement of any of the other soak solutions did not result in any changes in the rate of expansion.

As it was already mentioned in connection with the discussion of Figure 6 , the $\mathrm{MgCl}_{2}$ and $\mathrm{CaCl}_{2}$ do not contribute to the ASR, and thus, the observed expansions should be attributed to the changes in the matrix itself. The comparison of expansion of mortar bars with Ottawa sand and Jobe sand during the long exposure period is shown in Figure 8.

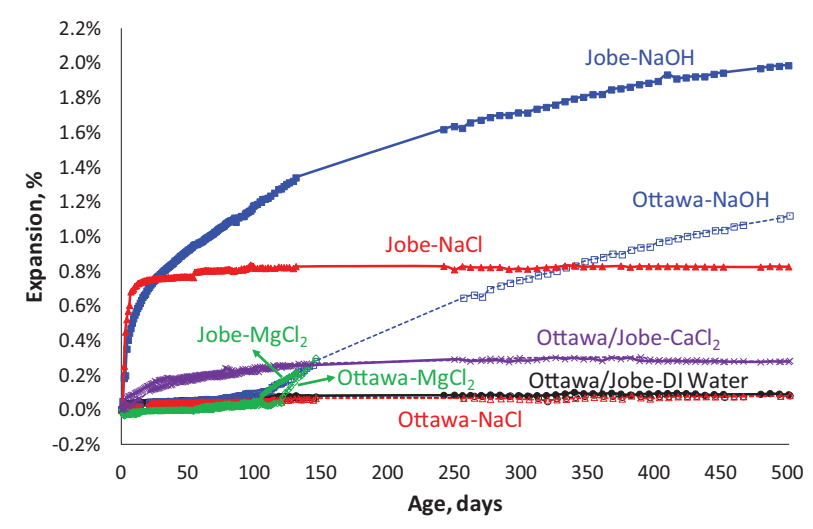

Figure 8. Comparison of expansion of mortar bars with Ottawa sand and Jobe sand during the long exposure period ( $\sim 500$ days). 
The expansion of the mortar bars stored in the DI water was about $0.08 \%$, and it was independent of the type of aggregate (i.e., reactive or nonreactive) used to prepare the test specimens. Similarly, the expansions of the mortar bars stored in the $\mathrm{CaCl}_{2}$ solution were also comparable (around $0.28 \%$ ) for both the nonreactive and reactive sets. On the other hand, the specimens stored in the $\mathrm{MgCl}_{2}$ solution showed a very different behavior. Specifically, the rate of expansion of mortar bars with the reactive (Jobe) sand started increasing after about 102 days of exposure with the expansion, eventually reaching the level of $0.22 \%$ at 131 days. At this point, the specimens disintegrated. A very similar behavior was also observed for mortar bars with nonreactive aggregate (Ottawa sand) except that these specimens reached a slightly higher level of ultimate expansion (about $0.3 \%$ ) and lasted a little bit longer (146 days) before disintegrating.

Figure 9 shows the loosened stud in the disintegrating Ottawa sand mortar bar exposed to $\mathrm{MgCl}_{2}$ solution for 146 days. Figures 10 and 11 show cracking and bending of mortar bars with, respectively, Ottawa and Jobe sand, stored in $\mathrm{MgCl}_{2}$ solution.

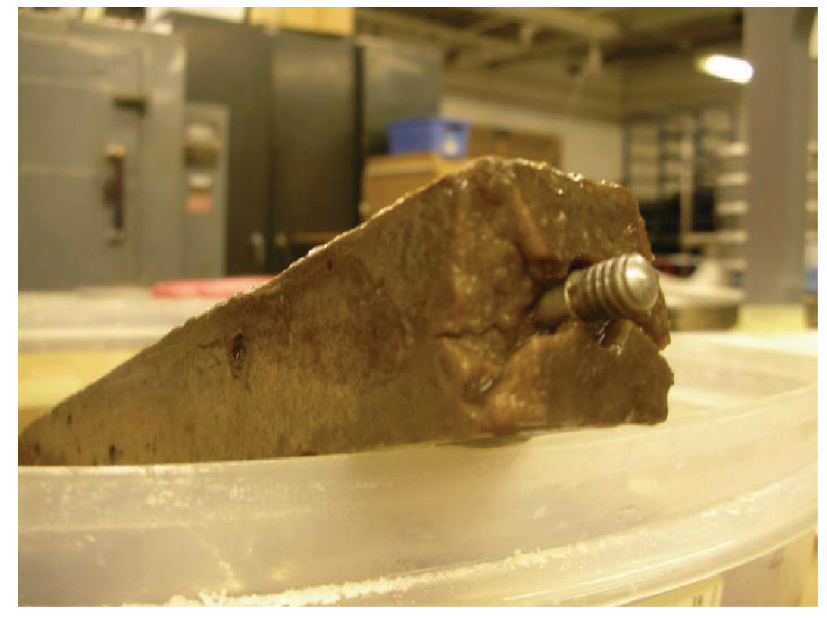

Figure 9. The loosened stud in mortar bar with Ottawa sand after 146 days of storage in the $25 \mathrm{wt} \% \mathrm{MgCl}_{2}$ solution.

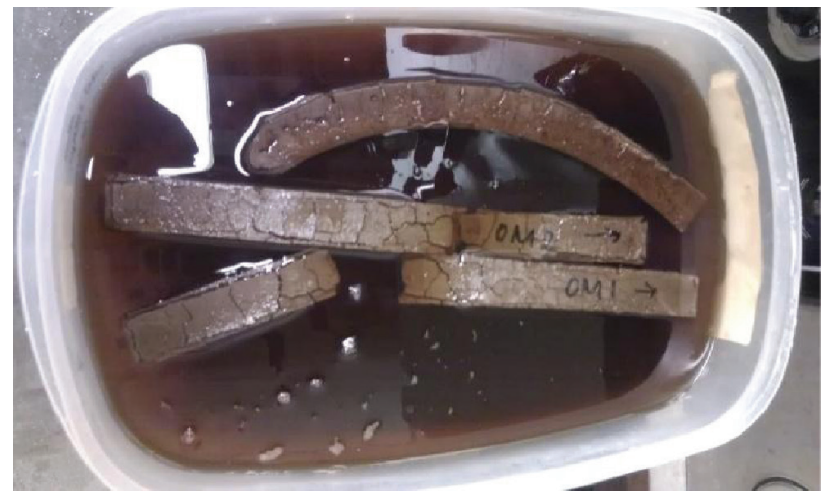

Figure 10. Cracking and bending of mortar bars with Ottawa sand after 257 days of storage in the $25 \mathrm{wt} \% \mathrm{MgCl}_{2}$ solution.

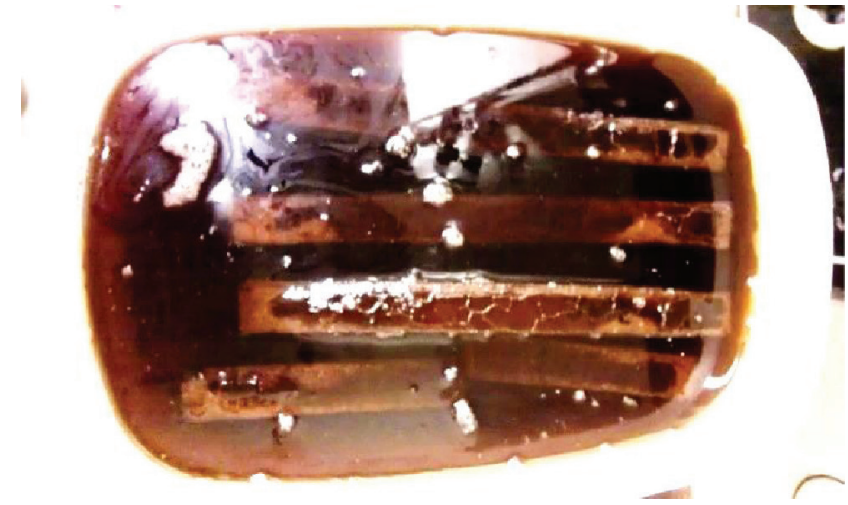

Figure 11. Cracking and bending of mortar bars with Jobe sand after 242 days of storage in the $25 \mathrm{wt} \% \mathrm{MgCl}_{2}$ solution.

The ultimate (500 days) expansion of mortar bars with Ottawa sand stored in $\mathrm{NaCl}$ solution was quite similar (about $0.08 \%$ ) to the expansion of specimens stored in the DI water. The 500 days expansion of mortar bars with the Jobe sand stored in the $\mathrm{NaCl}$ solution $(0.83 \%)$ was about $0.75 \%$ higher than the expansion of Ottawa sand specimens $(0.08 \%)$ stored in the $\mathrm{NaCl}$ solution for the same period.

After 110 days of exposure, the expansion rates of the mortar bars with Ottawa sand and Jobe sand stored in $\mathrm{NaOH}$ solution were almost the same. Although cracks were found at 242 days in the specimens with Jobe sand (Figure 12), the mortar bars with either Ottawa sand or Jobe sand did not disintegrate even after 500 days of exposure. After 500 days of storage in the $\mathrm{NaOH}$ solution, the mortar bars with Jobe sand developed about $0.87 \%$ higher expansion than bars with Ottawa sand.

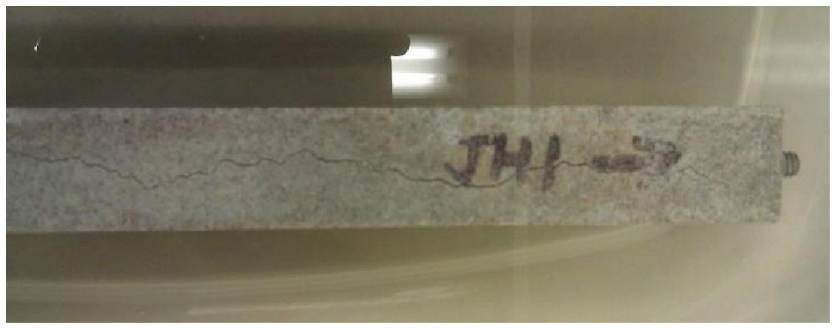

Figure 12. The crack on the surface of the specimen with Jobe sand after 242 days of storage in $1 \mathrm{~N} \mathrm{NaOH}$ solution.

\section{ANALYSIS AND DISCUSSION}

The experimental results presented in this article show that there are no significant differences in expansion of mortar bars with reactive aggregate (Jobe sand) and the bars with nonreactive aggregate (Ottawa sand) stored in DI water for either short or long exposure periods. Similar conclusions can also be drawn from the analysis of the test results obtained from the bars stored in $\mathrm{MgCl}_{2}$ solution and $\mathrm{CaCl}_{2}$ solutions. On the 
other hand, significant differences were observed in the expansion of mortar bars with both reactive and nonreactive aggregates stored in $\mathrm{NaCl}$ solution. These differences were evident in the test results from both short and long exposure periods.

These findings imply that magnesium $\left(\mathrm{Mg}^{2+}\right)$ and calcium $\left(\mathrm{Ca}^{2+}\right)$ ions do not seem to influence the ASR, while sodium ions $\left(\mathrm{Na}^{+}\right)$play an important role with respect to initiation and acceleration of ASR at high temperature of $80^{\circ} \mathrm{C}$. In general, during the first 130 days of exposure, the $\mathrm{Ca}^{2+}$ ions were observed to cause higher expansion than $\mathrm{Mg}^{2+}$ ions, irrespective of whether the reactive or nonreactive aggregates was used to prepare the mortar bars.

Chloride ions $\left(\mathrm{Cl}^{-}\right)$did not appear to play any role in influencing the ASR when they were accompanying the $\mathrm{Mg}^{2+}$ or $\mathrm{Ca}^{2+}$ ions. However, when comparing the expansion of mortar bars with reactive aggregate stored in $\mathrm{NaCl}$ and $\mathrm{NaOH}$ solution, the higher expansion rate of bars stored in $\mathrm{NaCl}$ than in $\mathrm{NaOH}$ solutions during the first 8 days of exposure indicates that $\mathrm{Cl}^{-}$may contribute to acceleration of ASR in the presence of $\mathrm{Na}^{+}$ions.

Moreover, the expansion rate of mortar bars prepared with Ottawa sand stored in $\mathrm{NaOH}$ solution started to increase after about 110 days of exposure. At this point, the rate of expansion of these bars was quite similar to the rate of expansion of bars with Jobe sand. This shows that given enough time, the ASR might be initiated even in the system with nominally nonreactive aggregate.

\section{CONCLUSIONS AND RECOMMENDATIONS}

\subsection{Conclusions}

The analysis of the results from this experimental study leads to the following general observations and conclusions:

- The mortar bars with reactive aggregate (Jobe sand) exposed to $\mathrm{NaCl}$ solution developed high expansion rate during the first 8 days of exposure.

- Based on the results of the long exposure test, it seems that only $\mathrm{NaCl}$ can initiate or accelerate the ASR. Exposure to $\mathrm{MgCl}_{2}$ and $\mathrm{CaCl}_{2}$ solutions does not seem to contribute to ASR.

- The mortar bars prepared with either of the two sands (nonreactive Ottawa sand or reactive Jobe sand) and stored in the $\mathrm{MgCl}_{2}$ solution cracked and disintegrated after about 130-150 days of exposure. This implies that the observed expansions should be attributed solely to the effect of this deicer on the cement paste itself.

- The test method used in this study provided significant insight into the effects of long-term deicer exposure on the ASR and the durability of the cement matrix itself.

\subsection{Recommendations}

Based on the results of this research, it appears that further valuable information may be obtained by conducting the following investigations:

- Pore solution and microscopic analyses will help in determining the nature of the mechanism of mortar degradation by identifying the chemical reactions occurring within the aggregates and cement paste.

- The experiments that can simulate the environmental conditions associated with the use of deicers (such as F/T and W/D tests) will provide more realistic correlation between the extent of ASR and type of deicing chemicals used.

\section{REFERENCES}

ASTM Standard C1260. (2007). Standard test method for potential alkali reactivity of aggregates (mortar-bar method). Annual Book of ASTM Standards 04.02, West Conshohocken, Pennsylvania, United States.

ASTM Standard C305. (2006). Standard practice for mechanical mixing of hydraulic cement pastes and mortars. Annual Book of ASTM Standards 04.01, West Conshohocken, Pennsylvania, United States.

Berube, M. A., \& Frenette, J. (1994). Testing concrete for $\mathrm{AAR}$ in $\mathrm{NaOH}$ and $\mathrm{NaCl}$ solutions at $38^{\circ} \mathrm{C}$ and $80^{\circ} \mathrm{C}$. Cement and Concrete Composites, 16(3), 189-198.

Desai, P. (2010). Alkali silica reaction under the influence of chloride based deicers. Master thesis, Clemson University, South Carolina, United States, $75 \mathrm{p}$.

Ghajar-Khosravi, S. (2011). Potassium acetate deicer and concrete durability. Master thesis, University of Toronto, Ontario, Canada, $201 \mathrm{p}$.

Kawamura, M., Takeuchi, K., \& Sugiyama, A. (1994). Mechanisms of expansion of mortars containing reactive aggregate in $\mathrm{NaCl}$ solution. Cement and Concrete Research, 24(4), 621-632.

Kawamura, M., \& Ichise, M. (1990). Characteristics of alkali-silica reaction in the presence of sodium and calcium chloride. Cement and Concrete Research, 20(5), 757-766. 